\title{
Phosphorylation of eIF4E by Mnk-1 enhances HSV-1 translation and replication in quiescent cells
}

\author{
Derek Walsh and Ian Mohr ${ }^{1}$ \\ Department of Microbiology and NYU Cancer Institute, New York University School of Medicine, \\ New York, New York 10016, USA
}

\begin{abstract}
Although the activity of the translation initiation factor eIF4F is regulated in part by translational repressors (4E-BPs) that prevent incorporation of eIF4E, the cap-binding protein, into the initiation complex, the contribution of eIF4E phosphorylation to translational control remains controversial. Here, we demonstrate that the herpes simplex virus-1 (HSV-1) ICP0 gene product, a multifunctional transactivator of viral gene expression with ubiquitin E3 ligase activity that is important for vegetative replication and reactivation of latent infections, is required to stimulate phosphorylation of eIF4E as well as 4E-BP1, and promote assembly of eIF4F complexes in infected cells. Furthermore, 4E-BP1 is degraded by the proteasome in an ICP0-dependent manner, establishing that the proteasome can control 4E-BP1 steady-state levels. Preventing eIF4E phosphorylation by inhibiting the eIF4E kinase mnk-1 dramatically reduced viral replication and the translation of viral polypeptides in quiescent cells, providing the first evidence that phosphorylation of eIF4E by mnk-1 is critical for viral protein synthesis and replication. Thus, in marked contrast to many viruses that inactivate eIF4F, HSV-1 stimulates eIF4F complex assembly in quiescent, differentiated cells; moreover, this is important for viral replication, and may be crucial for HSV-1 to initiate its productive growth cycle in resting cells, such as latently infected neurons.
\end{abstract}

[Keywords: eIF4E phosphorylation; translation; HSV-1 replication; 4E-BP1 degradation]

Received January 12, 2004; revised version accepted February 23, 2004.

As obligate intracellular parasites, viruses are dependent on the translational machinery of the host. To ensure their translation, viral mRNAs must effectively compete with host mRNAs for access to limiting amounts of translation initiation factors. Although a variety of strategies resulting in impaired translation of host mRNAs and enhanced synthesis of viral polypeptides have been described for several viruses (for review, see Schneider and Mohr 2003), relatively little is known about how herpesviruses interact with the cellular translation machinery.

Herpes simplex virus-1 (HSV-1), a large, DNA virus containing at least 80 open reading frames (ORFs), establishes life-long latent infections in sensory neurons that periodically "reactivate," leading to episodes of productive viral growth (for review, see Roizman and Knipe 2001). Throughout the course of these lytic replication cycles, initiating in neurons and subsequently spreading to the epithelial cells they innervate, the virus reprograms the infected host cell to produce viral polypep-

${ }^{1}$ Corresponding author.

E-MAIL ian.mohr@med.nyu.edu; FAX (212) 263-8276.

Article and publication are at http://www.genesdev.org/cgi/doi/10.1101/ $\operatorname{gad} .1185304$ tides. To accomplish this, HSV-1 must both seize control of the cellular translational machinery and inhibit a global host response aimed at inactivating key components of the protein synthetic apparatus.

Although two known viral gene products, acting at different stages of the HSV-1 lifecycle, facilitate the abundant synthesis of viral proteins by preventing the cellular antiviral response from inactivating the translation initiation factor eIF2, host polypeptide synthesis is dramatically impaired (Mulvey et al. 2003). The shutoff of host protein synthesis is complex, and is thought to result from a reduction in the transcription of host genes (for review, see Roizman and Knipe 2001), the inhibition of host RNA splicing (Sciabica et al. 2003), and the destabilization of mRNA by the viral vhs gene product (Elgadi et al. 1999; Everly et al. 2002). Although vhs does not discriminate between viral and cellular RNA, its selectivity for mRNA molecules is mediated through an association with eIF4H, which, in turn, stimulates eIF4A, a component of the eIF4F initiation complex (Feng et al. 2001).

The translation initiation factor eIF4F (for review, see Gingras et al. 1999) is a complex of cellular polypeptides whose core is composed of the cap-binding protein (eIF4E), a large scaffolding subunit (eIF4G isoforms 1 or 
2), and an RNA helicase (eIF4A). In addition, eIF4B or eIF4H stimulate the activity of eIF4A, functioning as processivity factors for the helicase (for review, see Rogers et al. 2002). Because this complex binds capped mRNA and recruits 40S ribosomal subunits bound to eIF3, it is a prime target for regulating translation initiation. Depending on their abundance, a family of small eIF4E-binding proteins (4E-BPs) can sequester eIF4E in a phosphorylation-dependent manner (for review, see Gingras et al. 2001). In their hypophosphorylated form, 4EBPs inhibit cap-dependent translation. Hyperphosphorylation of the 4E-BPs by the mTOR kinase in response to a variety of environmental cues results in the release of eIF4E, allowing the cap-binding protein to associate with eIF4G and assemble an active eIF4F complex. In addition, the cap-binding protein eIF4E is phosphorylated by the eIF4G-associated kinase mnk-1 (Fukunaga and Hunter 1997; Waskiewicz et al. 1997, 1999; Pyronnet et al. 1999; Scheper et al. 2001). Presently, however, although some reports claim to correlate increased translation rates with eIF4E phosphorylation (Bonneau and Sonenberg 1987; Huang and Schneider 1991; Boal et al.
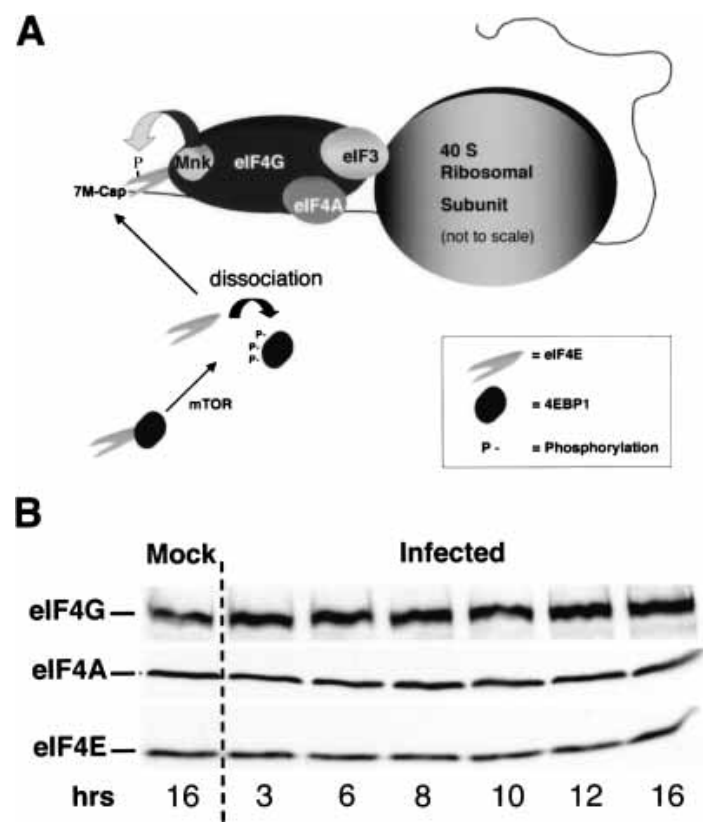

Figure 1. Steady-state levels of key eIF4F components are not significantly altered in HSV-1-infected cells. (A) The translation initiation factor eIF4F is composed of the cap-binding protein eIF4E, the eIF4A RNA helicase, and the large scaffolding protein eIF4G. The 40S ribosome subunit is recruited to the $5^{\prime}$-end of the mRNA through an interaction between eIF4G and eIF3. eIF4E is phosphorylated by the cellular eIF4G-associated kinase mnk-1. The 4E-BP family of repressor proteins binds eIF4E in resting cells, preventing its incorporation into the eIF4F complex. Upon phosphorylation by the mTOR kinase, the eIF4E4E-BP1 complex is dissolved, releasing free eIF4E. (B) Whole-cell lysates from either mock-infected or HSV-1-infected (MOI = 10) U373 cells were prepared at various times postinfection. The samples were fractionated by SDS-PAGE and transferred to a membrane, which was subsequently cut into strips and probed with the indicated antibodies.
1993; Morley et al. 1993; Beretta et al. 1998; Pyronnet et al. 2001; Takei et al. 2001; Dyer et al. 2003), other studies have been unable to demonstrate any effects of eIF4E phosphorylation on translation (Knauf et al. 2001; McKendrick et al. 2001; Morley and Naegele 2002). As HSV-1 transcripts are capped, we sought to investigate the effects of viral infection on the components of the eIF4F complex.

Although infection with numerous RNA or DNA viruses results in impaired eIF4F function, we now demonstrate that HSV-1 infection stimulates rapid phosphorylation of eIF4E and 4E-BP1, enhancing the assembly of active eIF4F complexes. These alterations to the eIF4F complex require the ICP0 gene product, a critical viral regulatory protein that is important for productive viral growth and efficient reactivation of latent infections. Preventing eIF4E phosphorylation by inhibiting mnk-1, the cellular eIF4E kinase, significantly reduced HSV-1 mRNA translation and viral replication in quiescent, primary human cells. Furthermore, following its phosphorylation by the cellular mTOR kinase, steadystate levels of 4E-BP1 were also reduced during infection in an ICPO-dependent manner. The proteasome inhibitor, MG132, prevented the reduction in 4E-BP1 levels, demonstrating that the proteasome can regulate the stability of the 4E-BP1 translational repressor. Together, these findings suggest that activating the translation machinery is critical for efficient viral growth in resting cells such as neurons, which harbor latent virus, and terminally differentiated epithelial cells. Viral functions responsible for stimulating the cellular translation machinery may be worth considering as targets for the development of new antiviral agents.

\section{Results}

Steady-state levels of eIF4F components are not altered following HSV-1 infection

To begin characterizing the effects of HSV-1 infection on the eIF4F complex (Fig. 1A), the steady-state levels of the individual components, eIF4G, eIF4A, and eIF4E, in infected cells were evaluated by immunoblotting. Figure $1 \mathrm{~B}$ demonstrates that no significant alterations in levels of the eIF4F components were observed through a 16-h time course. This includes time points late in the infectious program where viral proteins are predominately synthesized while host protein synthesis is significantly impaired (Mulvey et al. 2003). Thus, the inhibition of host protein synthesis observed in HSV-1 infected cells does not involve alterations to the steady-state levels of the individual eIF4F components.

\section{Stimulation of eIF4E phosphorylation in HSV-1-infected cells}

As the overall quantity of eIF4E, eIF4G, and eIF4A remained unchanged following infection with HSV-1, the effect of viral infection on eIF4E phosphorylation was 
investigated. To examine eIF4E phosphorylation in response to HSV-1 infection, lysates from mock-infected or HSV-1-infected cells were fractionated by isoelectric focusing (IEF), as phosphorylated eIF4E exhibits reduced mobility under these conditions, and analyzed by immunoblotting. In primary human cells and a variety of established cell lines, HSV-1 infection resulted in the increased accumulation of phosphorylated eIF4E as early as $6 \mathrm{~h}$ postinfection, reaching peak levels at $\sim 8 \mathrm{~h}$ postinfection (Fig. 2A).

Whereas the cellular kinase mnk-1 is responsible for phosphorylating eIF4E, mnk-1 can be activated by either the ERK or p38 kinases (Fukunaga and Hunter 1997; Waskiewicz et al. 1997; Wang et al. 1998). p38 was reported to be activated following infection of either murine 3T3 cells or human U2OS osteosarcoma cells with HSV-1, and no change was observed in ERK activity in a
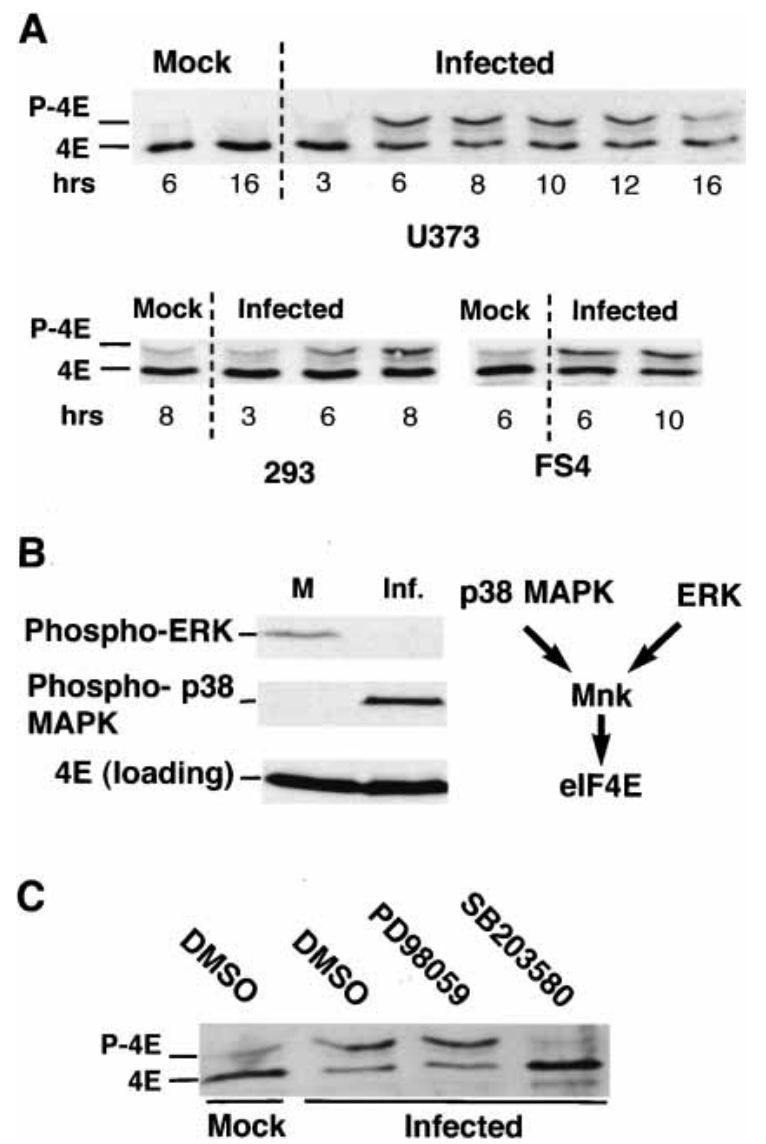

Figure 2. Activation of the eIF4E kinase mnk by p38 in HSV1 -infected cells. Total protein was isolated from mock-infected or HSV-1-infected $(\mathrm{MOI}=10) \mathrm{U} 373,293$, or FS4 cells at the indicated times. $(A)$ Samples were fractionated by isoelectric focusing (IEF) and analyzed by immunoblotting with an eIF4E antibody. (B) Samples from mock-infected (M) or HSV-1-infected (Inf.) primary FS4 cells $(9 \mathrm{~h}$ postinfection) were fractionated by SDS-PAGE and analyzed by immunoblotting with the indicated antisera. $(C)$ Samples (as described in $B$ ) isolated from cultures treated with either DMSO, the ERK inhibitor PD98059, or SB203580 were fractionated by IEF and analyzed by immunoblotting as in $A$. variety of established cell lines (McLean and Bachenheimer 1999; Zachos et al. 1999). To determine which of these kinases was active in primary human cells infected with HSV-1, total cellular protein, isolated from uninfected and infected cells, was fractionated by SDS-PAGE and analyzed by immunoblotting. Although phosphorylated ERK was only detected in uninfected cells, phosphorylated p38 was observed exclusively in HSV-1-infected cells (Fig. 2B). Contrary to the findings in established cell lines that display measurable, but unchanged levels of ERK activity following HSV-1 infection (McLean and Bachenheimer 1999), we do not detect any activated ERK following infection of primary cells. In fact, phosphorylated ERK levels actually drop significantly; suggesting that HSV-1 infection efficiently switches the kinase responsible for activating mnk from ERK to p38. Moreover, the p38 inhibitor SB203580 prevented phosphorylation of eIF4E in primary human cells infected with HSV-1, whereas PD98059, an inhibitor of ERK activation, did not (Fig. 2C). Importantly, the mnk-1 inhibitor CGP57380 prevents eIF4E phosphorylation as well (Fig. 8A, below). Identical results were obtained in NHDF cells, an independent strain of primary human fibroblasts (data not shown). Thus, given that HSV-1 infection activates p38 and down-regulates ERK, eIF4E phosphorylation results from the activation of p38, which, in turn, stimulates the eIF4E kinase mnk-1.

Phosphorylation of $4 E-B P 1$ results in its degradation by the proteasome in HSV-1-infected cells

When present in sufficient quantities, the cellular 4Ebinding proteins (4E-BPs) in their hypophosphorylated form can sequester eIF4E and regulate its availability (for review, see Gingras et al. 2001). To evaluate the state of 4E-BP1 phosphorylation in HSV-1-infected cells, phosphorylated 4E-BP1 isoforms present in lysates prepared from mock- or HSV-1-infected cells were fractionated by SDS-PAGE in $17.5 \%$ gels and visualized by immunoblotting. Following infection of either primary human cells or several established cell lines with HSV-1, slower migrating, hyperphosphorylated forms of 4E-BP1 accumulated, and their appearance was blocked by rapamycin, an inhibitor of the cellular mTOR kinase. (Fig. 3). Thus, in addition to inducing eIF4E phosphorylation, HSV-1 infection results in hyperphosphorylation of 4EBP1. Moreover, 4E-BP1 steady-state levels appear to undergo a significant decrease upon infection (Fig. 3B).

To compare levels of 4E-BP1 present in infected versus uninfected cells, total protein samples were fractionated in $7.5 \%$ polyacrylamide gels. Under these conditions, the multiple phosphorylated isoforms are not resolved and a reduction in 4E-BP1 steady-state levels is clearly observed (Fig. 3C). In contrast, the overall amount of eIF4A remains relatively unchanged (Fig. 3C). Treatment of infected cells with either the mTOR inhibitor rapamycin or the proteasome inhibitor MG132 prevented the reduction in 4E-BP1 levels following HSV-1 infection. Moreover, the reduction in 4E-BP1 overall levels cannot be caused by the selective destruction of the hypophos- 
A
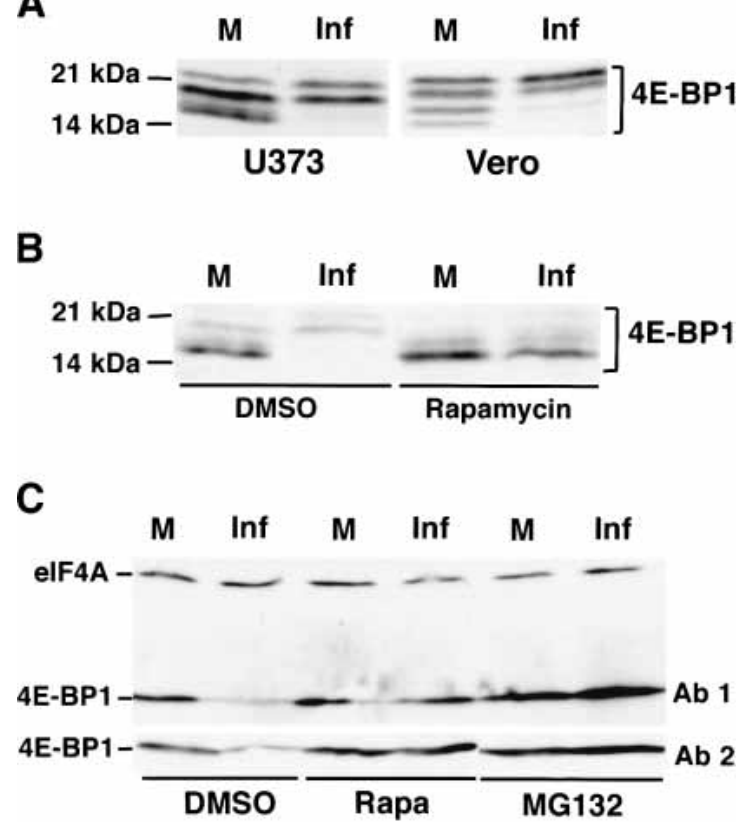

Figure 3. Phosphorylation of 4E-BP1 and its degradation by the proteasome in HSV-1-infected cells. (A) Total protein from mock-infected (M) and HSV-1-infected (Inf) U373 or Vero cells ( $\mathrm{MOI}=10 ; 8 \mathrm{~h}$ postinfection) was fractionated by SDS-PAGE in $17.5 \%$ gels and analyzed by immunoblotting with anti-4E-BP1. Molecular weight standards (in kilodaltons) appear on the left. (B) As in $A$, except NHDF cells (MOI $=10 ; 9 \mathrm{~h}$ postinfection) either treated with rapamycin or untreated were used. $(C)$ Total protein from mock- and HSV-1-infected NHDF cells (MOI $=10$; $9 \mathrm{~h}$ postinfection) treated with either rapamycin or MG132 or untreated was fractionated by SDS-PAGE in 7.5\% gels (which do not resolve phosphorylated 4E-BP1 isoforms), and the steadystate levels of 4E-BP1 and eIF4A (loading control) were evaluated by immunoblotting. $\mathrm{Ab} 1$ and $\mathrm{Ab} 2$ refer to two independent preparations of anti 4E-BP1 polyclonal antisera.

phorylated forms of 4E-BP1, as these forms accumulate in infected cells treated with rapamycin (Fig. 3B). This establishes that the observed reduction in 4E-BP1 steadystate levels occurs as a result of 4E-BP1 phosphorylation followed by proteasomal degradation. This is the first demonstration that upon phosphorylation, the translational repressor 4E-BP1 becomes a substrate for the proteasome.

Stimulation of eIF4F complex assembly in quiescent cells infected with HSV-1

As both eIF4G and the translational repressor 4E-BP1 both bind to the same surface of eIF4E, release of 4E-BP1 is required to promote the assembly of active eIF4F complexes on the 5 '-end of capped mRNAs (Haghighat et al. 1995; Mader et al. 1995; Marcotrigiano et al. 1999). The differential association of these factors with eIF4E can be evaluated by batch chromatography of cell-free lysates on 7-methyl GTP Sepharose followed by immunoblotting to identify the various bound polypeptides. In an asynchronously growing population, little change is detected in the overall levels of eIF4E and eIF4G capable of associating with the affinity resin upon infection with HSV-1, whereas the translational repressor 4E-BP1 is released and is no longer detected in the fraction bound to the resin (Fig. 4A). 4E-BP1 is retained on the beads in the presence of rapamycin, presumably because inhibiting mTOR prevents 4E-BP1 phosphorylation and allows its continued association with eIF4E (Fig. 4A). In cells growth-arrested by serum starvation, while similar quantities of eIF4E and hypophosphorylated 4E-BP1 remain associated with the resin, the overall amount of eIF4G present is dramatically reduced relative to the amount detected in complexes isolated from unstarved cells (Fig. 4B). This is consistent with the reduction of eIF4F activity and translation rates observed in quiescent cells (Stanners and Becker 1971; Thomas and Gordon 1979; Thomas et al. 1981; Thomas and Thomas 1986). Following infection with HSV-1, the 4E-BP1 repressor is released from eIF4E and a sharp increase in the amount of eIF4G associated with eIF4E is observed, suggesting that HSV-1 encodes a function that promotes the assembly of active eIF4F complexes in resting cells as the overall levels of eIF4G remain unchanged (Fig. 4B). Enhanced assembly of eIF4F complexes was also observed in the presence of the p38 inhibitor SB203580 or the mnk-1 inhibitor CGP57380, both of which prevent eIF4E phosphorylation (Fig. 4C), and is consistent with other reports demonstrating that inhibiting eIF4E phosphorylation does not alter the recovery of eIF4G in the eIF4F complex (Morley and Naegele 2002). This likely reflects that eIF4E is phosphorylated by mnk-1 once assembled into the eIF4F complex (Tuazon et al. 1990; Pyronnet et al. 1999). Furthermore, treatment of infected cells with rapamycin prevents the phosphorylation of 4E-BP1 and its release from eIF4E but does not completely abrogate the ability of eIF4E to associate with eIF4G (Fig. 4B). This suggests that $4 \mathrm{E}-\mathrm{BP} 1$ is not present in sufficient quantities to sequester all of the available eIF4E. It is therefore unlikely that the relief of 4E-BP1-mediated repression plays a dominant role in stimulating translation following infection of quiescent, primary human cells with HSV-1. Similar conclusions regarding the abundance of 4E-BP1 have been reached in other biological systems (Feigenblum and Schneider 1996; Morley and McKendrick 1997; Cuesta et al. 2000a).

Phosphorylation of eIF4E and 4E-BP1 and degradation of $4 E-B P 1$ require viral gene expression

To begin defining the point in the viral lifecycle at which eIF4E and 4E-BP1 are phosphorylated, phosphonoacetic acid (PAA) was used to inhibit viral DNA synthesis, blocking progression into the late phase of the infection (Fig. 5A). Figure 5B demonstrates that p38 is activated, and eIF4E and 4E-BP1 are both phosphorylated in infected cells treated with PAA, suggesting that these modifications are induced at earlier times in the viral replicative program. The failure of the Us11 protein, a viral late protein whose expression is dependent on viral 
Walsh and Mohr

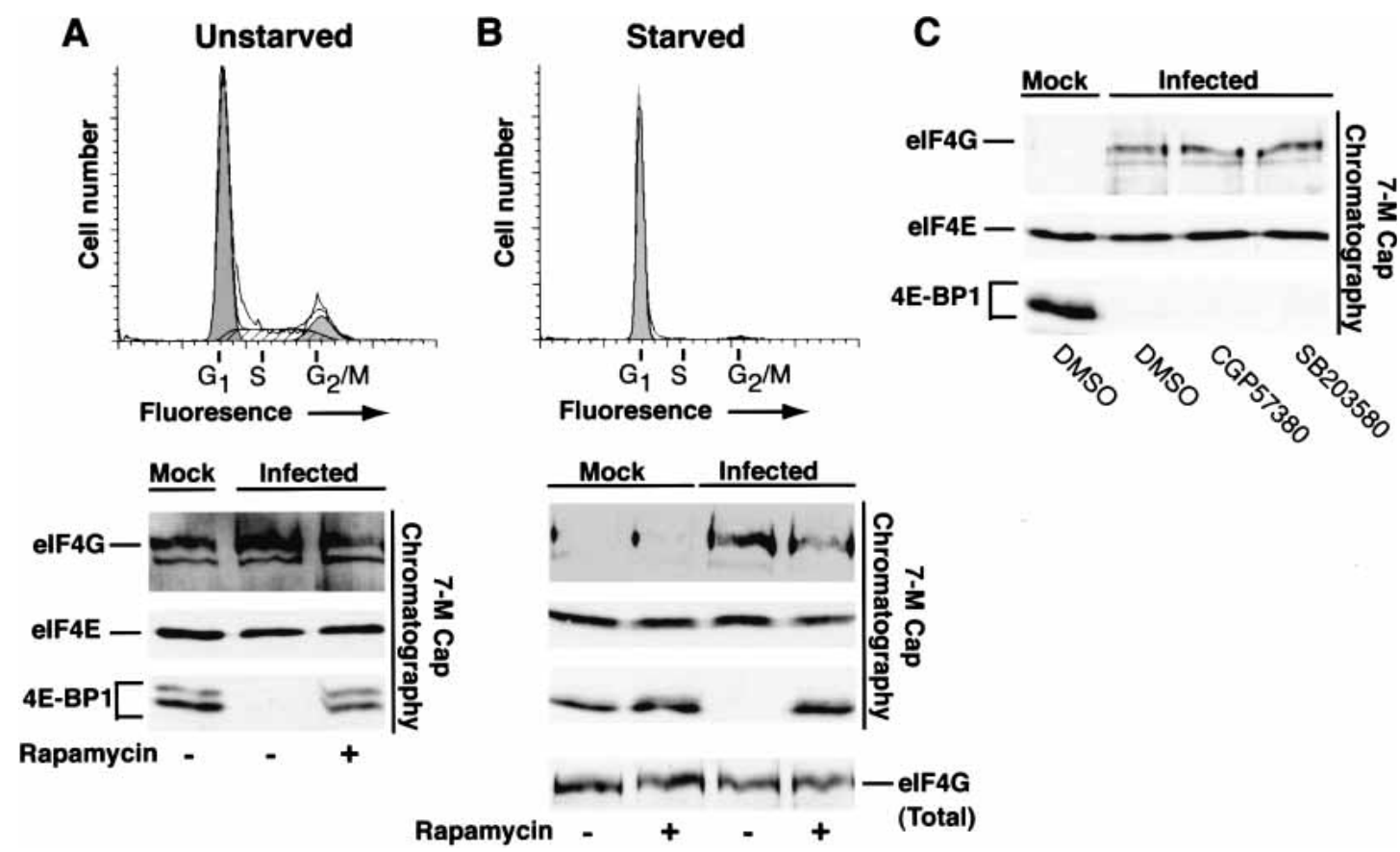

Figure 4. Assembly of active eIF4F complexes in quiescent cells is enhanced following HSV-1 infection. Unstarved, asynchronous NHDF cells $(A)$ and serum-starved, growth-arrested primary human NHDF cells $(B)$ were either mock infected or infected with wild-type (WT) HSV-1 in the presence of DMSO or rapamycin. After $12 \mathrm{~h}$, cell extracts were prepared and proteins bound to 7-methyl GTP Sepharose 4B were fractionated by SDS-PAGE, immunoblotted and visualized with the indicated antibodies. A sample of unfractionated extract prepared from starved cells was also analyzed by immunoblotting to determine the overall levels of eIF4G (eIF4G total). FACs profiles of uninfected serum-starved $(72 \mathrm{~h})$ or unstarved cells stained with propidium iodide appear above the immunoblots and peaks representing cells in various phases of the cell cycle $\left(\mathrm{G}_{1}, \mathrm{~S}, \mathrm{G}_{2} / \mathrm{M}\right)$ are indicated. $(C)$ Serum-starved, growtharrested NHDF cells were treated with either DMSO, the mnk-1 inhibitor CGP57380, or the p38 inhibitor SB203580. Extracts were chromatographed on 7-methyl GTP Sepharose and analyzed as described above in $A$ and $B$.

DNA synthesis, to accumulate in PAA-treated cells attests to the effectiveness of this treatment (Fig. 5B). Entry of the virus into cells, however, was not sufficient to trigger phosphorylation of eIF4E and 4E-BP1, as UV-inactivated virus was unable to promote these modifications (Fig. 5A,C). Activation of p38, the kinase responsible for stimulating the eIF4E kinase mnk-1 in HSV-1infected cells, was also not observed in cells infected with UV-inactivated virus (Fig. 5C). Furthermore, because UV-inactivated virus can deposit functional virion components into infected cells (Fig. 5A), the presence of these virion components appears not to be sufficient to stimulate modification of eIF4E and 4E-BP1.

To rule out the possibility that UV treatment somehow damaged the virus preparation, we made use of a temperature-sensitive mutant, tsB7(B). As tsB7(B) virions can enter cells but are defective in uncoating at $39.5^{\circ} \mathrm{C}$, the viral DNA cannot enter the nucleus (Fig. 5A; Batterson et al. 1983). Although the tsB7 strain stimulates eIF4E and 4E-BP1 phosphorylation at $33.5^{\circ} \mathrm{C}$, it does not promote phosphorylation of these factors at $39.5^{\circ} \mathrm{C}$ (Fig. 6A). Phosphorylation of eIF4E and 4E-BP1 occurs at both temperatures in cells infected with wild-type HSV-1, although the magnitude of eIF4E phosphorylation is somewhat reduced at $39.5^{\circ} \mathrm{C}$ (Fig. 6A). In addition, 4E-BP1 degradation occurs at $33.5^{\circ} \mathrm{C}$, but not $39.5^{\circ} \mathrm{C}$ (Fig. 6B).
Thus, phosphorylation of eIF4E and 4E-BP1 and the degradation of 4E-BP1 occur early in the viral lifecycle and require the delivery of viral DNA into the nucleus. This suggests that viral gene expression is required.

Following infection of a cell that supports lytic replication, 5 HSV-1 immediate-early (IE) mRNAs are produced (for review, see Roizman and Knipe 2001). One of these RNAs encodes the ICP0 gene product. In addition to its role as a promiscuous transactivator of viral gene expression, the ICP0 protein contains an intrinsic E3 ubiquitin ligase activity, and associates with ND-10 structures, whereupon it promotes their disassembly (Van Sant et al. 2001; Boutell et al. 2002; for review, see Everett 2000). As the ICP0 protein has an established role in promoting protein degradation and was expressed early in the viral lifecycle, we investigated if the degradation of 4E-BP1 depended on ICP0 in HSV-1-infected cells. Primary human cells were mock-infected or infected with either an ICPO mutant virus (7134), or a virus in which the mutant ICPO allele was repaired (7134R). Total protein isolated from each sample was fractionated by SDS-PAGE in $7.5 \%$ gels and analyzed by immunoblotting with 4E-BP1 and eIF4A antibodies, the latter confirming that equal protein amounts were loaded in each lane. Figure 7A demonstrates that 4E-BP1 steadystate levels are unaffected following infection with an 
A

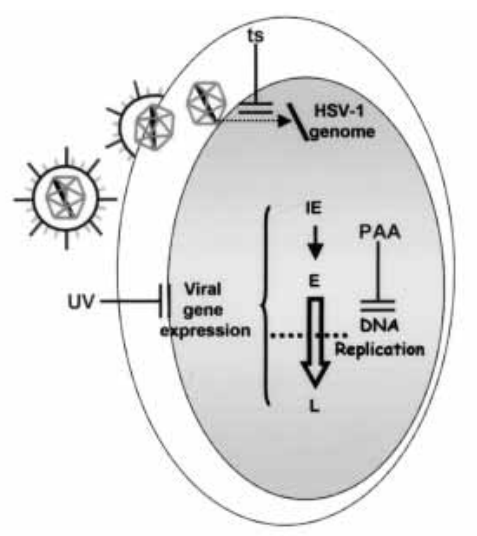

B

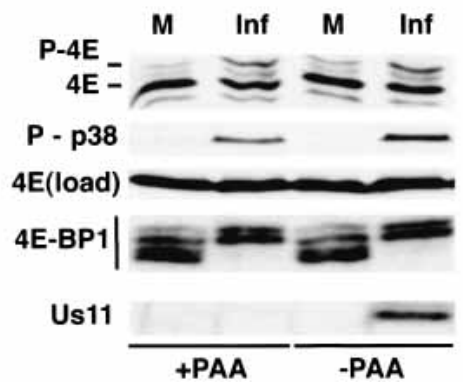

C
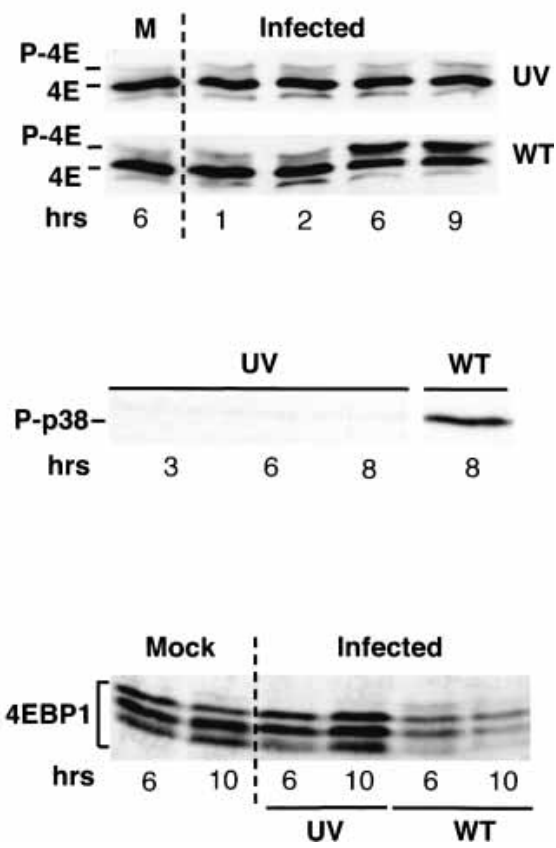

Figure 5. Phosphorylation of eIF4E and 4E-BP1 in HSV-1-infected cells occurs in the absence of true late-gene expression, but not in cells infected with UV-inactivated virus. (A) After fusion of the virion envelope with the plasma membrane, the HSV-1 nucleocapsid travels to the nuclear pore complex, and viral genomic DNA is released into the nucleus. Viral immediate early (IE) genes, primarily encoding transactivators of early (E) genes, are expressed first, whereas early gene products are mostly involved in viral DNA replication. Expression of a subclass of viral late genes $(\mathrm{L})$ depends on viral DNA replication and is blocked by PAA. At $39.5^{\circ} \mathrm{C}$, the tsB7(B) mutant is unable to deliver the viral genome into the nucleus, preventing expression of all viral genes (ts). Although capable of entering cells, UV-irradiated virus is also unable to express viral genes. (B) NHDF cells were either mock infected (M) or infected (Inf) with wild-type $(\mathrm{WT}) \mathrm{HSV}-1(\mathrm{MOI}=10)$ in the absence or presence of $300 \mu \mathrm{g} / \mathrm{mL}$ PAA. After 8 h, total protein was isolated, fractionated by SDS-PAGE or IEF (eIF4E phosphorylation), and analyzed by immunoblotting with the indicated antibodies. (C) U373 cells were either mock infected, infected $(\mathrm{MOI}=10)$ with wild-type HSV-1 (WT), or infected with UV-inactivated HSV-1 (UV). At the indicated times following infection, total protein was isolated and fractionated by IEF or $17.5 \%$ SDS-PAGE and analyzed by immunoblotting with the indicated antisera.

ICPO mutant virus, whereas cells infected with a virus in which the ICPO mutation was repaired efficiently degrade 4E-BP1. This establishes that the degradation of 4E-BP1 observed in HSV-1 infected cells requires the ICPO gene. Furthermore, eIF4E phosphorylation, p38 activation, and 4E-BP1 phosphorylation in infected cells were all dependent on a wild-type ICPO allele as well (Fig. 7B). Finally, analysis of eIF4E-associated proteins by batch adsorption to 7-methyl GTP Sepharose revealed that 4E-BP1 remains associated with eIF4E in lysates prepared from cells infected with an ICPO mutant, and an increase in the amount of eIF4G present in the fraction bound to the resin was not observed (Fig. 7C). In contrast, extracts prepared from cells infected with a virus in which the ICPO mutation was repaired did not contain detectable amounts of 4E-BP1 in the bound fraction and exhibited an increase in the overall amount of eIF4G bound to eIF4E (Fig. 7C). This establishes that ICPO mutants are unable to promote the assembly of active eIF4F complexes, raising the possibility that eIF4E phosphorylation is important for proper translational regulation and viral growth.
The activity of mnk-1, an eIF4E kinase, is required for efficient HSV-1 replication in quiescent human cells

It has been well established that ICPO mutant viruses are growth impaired in a variety of cultured cells at low doses of input viral particles (Stow and Stow 1986; Sacks and Schaffer 1987). Having just determined that phosphorylation of eIF4E and 4E-BP1 in infected cells depended on the ICP0 gene product, we proceeded to evaluate the importance of eIF4E and 4E-BP1 phosphorylation on the productive growth of HSV-1 by measuring viral replication in the presence and absence of SB203580, CGP57380, and rapamycin. At the doses tested, these compounds had no obvious effects on cell number and did not result in any observable cytopathic effect on the cells used in these experiments (D. Walsh and I. Mohr, unpub.), but were effective in preventing detectable eIF4E phosphorylation (SB 203580, CGP57380) or 4E-BP1 phosphorylation (rapamycin) in HSV-1-infected cells (Fig. 8A). Primary human cells were serum-starved for 72 $h$, such that $>98 \%$ of the cells were in the $G_{1}$ phase of the cell cycle as revealed by propidium iodide staining fol- 


\section{A}

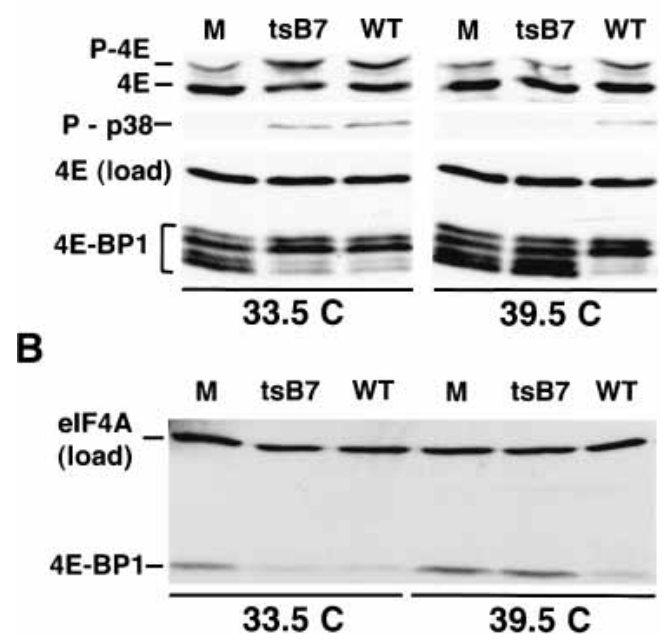

Figure 6. Modification of eIF4E and 4E-BP1 in HSV-1-infected cells requires viral gene expression. (A) NHDF cells were either mock infected $(\mathrm{M})$, infected with wild-type HSV-1 (WT), or infected $(\mathrm{MOI}=3)$ with the tsB7 mutant (ts) at the permissive $\left(33.5^{\circ} \mathrm{C}\right)$ or restrictive temperature $\left(39.5^{\circ} \mathrm{C}\right)$. After $8 \mathrm{~h}$, total protein was isolated, fractionated by IEF or SDS-PAGE, and analyzed by immunoblotting with the indicated antibodies. (B) As in $A$, except the polypeptides were resolved in a $7.5 \%$ SDSpolyacrylamide gel.

lowed by flow cytometry (Fig. 4), and subsequently infected with wild-type HSV-1. After allowing for multiple viral replication cycles over the course of $5 \mathrm{~d}$, a cell-free lysate was prepared by freeze thawing, and the amount of infectious virus produced was titered in Vero cells. A $10^{3}$-fold reduction in the amount of virus recovered from cultures treated with SB203580 was observed, demonstrating that activation of $\mathrm{p} 38$ is required for efficient replication of HSV-1 in quiescent primary human cells (Fig. 8B). To demonstrate that this effect was, to a large extent, due to inhibition of the downstream kinase mnk1 , the experiment was repeated using the specific mnk-1 inhibitor CGP57380. Under these conditions, the amount of virus recovered from CGP57380 treated cultures was reduced by a factor of $10^{2}$-fold relative to mock-treated cultures, establishing that activity of the eIF4E kinase mnk-1 is required for efficient viral replication in quiescent, primary human cells (Fig. 8B). The 10-fold greater inhibition observed with SB203580 suggests that activated p38 might be required for additional functions independent of mnk-1 activation. Preventing 4E-BP1 phosphorylation with rapamycin, however, only resulted in a $50 \%$ decrease in viral yield and was not deemed significant (Fig. 8B). This is consistent with our findings that $4 \mathrm{E}-\mathrm{BP} 1$ is not present in quantities sufficient to completely prevent eIF4G from associating with eIF4E (Fig. 4B), and therefore is unable to extinguish the translation of viral mRNAs in these primary human cells. Phosphorylation of eIF4E is therefore important for viral replication in quiescent cells, and is required to enhance viral growth at low input doses of virus.
To determine if decreased viral translation rates correlate with the observed reduction in viral replication, serum-starved cells treated with SB203580, CGP57380, rapamycin, or a solvent control (DMSO) were infected with HSV-1 at different input doses of virus and metabolically labeled for $1 \mathrm{~h}$ with ${ }^{35} \mathrm{~S}$ methionine and cysteine at $14 \mathrm{~h}$ postinfection. To distinguish virus-specific polypeptides from the enormous excess of host proteins in cultures that were infected with the lowest input dose of virus (multiplicity of infection $[\mathrm{MOI}]=0.01$ ), viral proteins were immunoprecipitated from whole-cell lysates using anti-HSV-1 polyclonal antisera prior to SDSPAGE. This IP step was not necessary for cultures infected with higher input doses of virus because the majority of cells are infected, and HSV-1 effectively inhibits host translation. Consistent with the observed reduction in viral replication, compounds that blocked eIF4E phosphorylation exhibited the strongest reduction in translation rates (Fig. 8B). Strikingly, however, the reduction in translation rates caused by SB203580 and CGP57380 di-

A
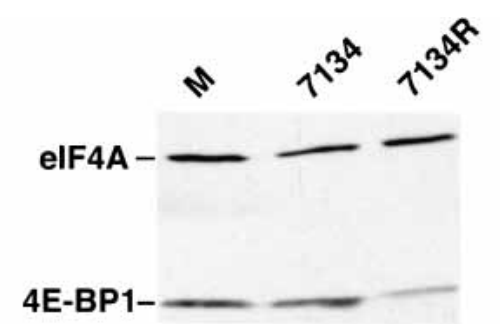

B

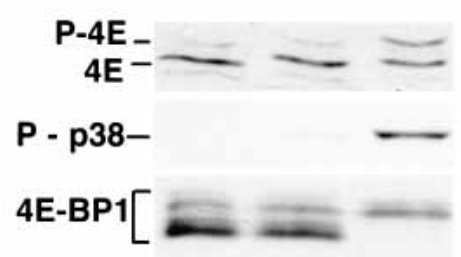

C

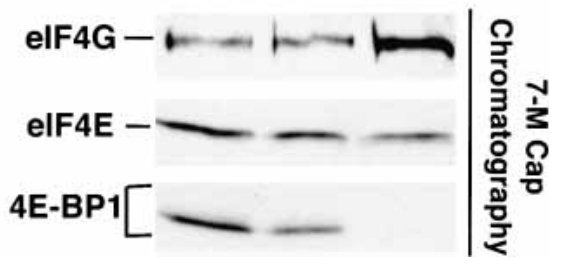

Figure 7. Stimulation of eIF4F complex assembly and modification of eIF4E and 4E-BP-1 in HSV-1-infected cells depends on the ICP0 protein. NHDF cells were either mock infected $(\mathrm{M})$, infected $(\mathrm{MOI}=3)$ with the ICPO null mutant 7134 , or infected with a virus in which the ICPO mutation was repaired (7134R). After $8 \mathrm{~h}$, total protein was isolated and fractionated by SDSPAGE or IEF, and analyzed by immunoblotting with the indicated antibodies. (A) 4E-BP1 is not degraded in NHDF cells infected with an ICPO deletion mutant. (B) eIF4E and 4E-BP1 are not phosphorylated in cells infected with an ICPO mutant, and p38 is not activated. $(C)$ Primary human fibroblasts (NHDF cells) were growth arrested by serum starvation and either mock infected or infected with 7134 or $7134 \mathrm{R}$. eIF4F complexes were isolated by adsorption to 7-methyl GTP Sepharose and analyzed as described in the legend to Figure 4. 
A

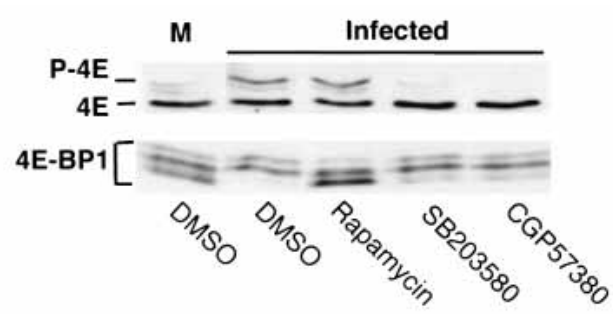

B

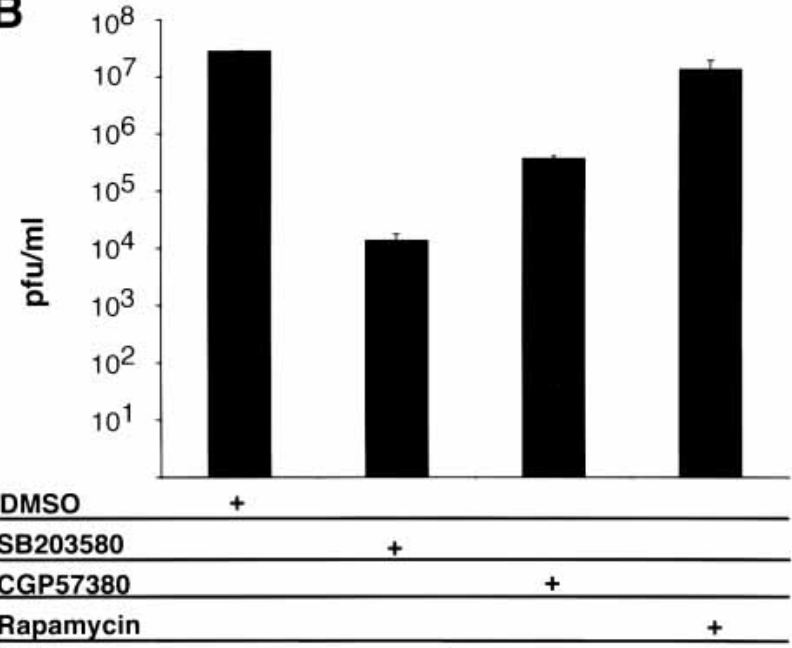

C
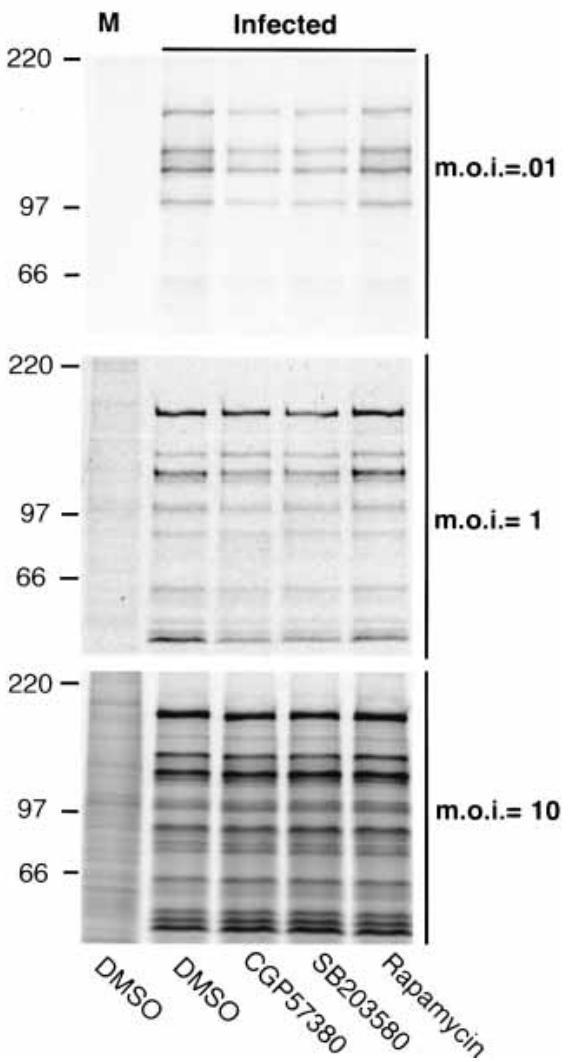

Figure 8. Inhibiting eIF4E phosphorylation significantly reduces HSV-1 replication and protein synthesis in quiescent cells infected at low input doses of virus. (A) Growth-arrested NHDF cells were either mock infected $(\mathrm{M})$ or infected with HSV-1 (MOI = 10; $15 \mathrm{~h}$ postinfection) in the presence and absence of the indicated inhibitors. eIF4E and 4E-BP1 in whole-cell lysates were detected by IEF or SDS-PAGE followed by immunoblotting with the appropriate antisera. (B) Primary human fibroblasts (NHDF cells) were growth arrested by serum starvation and infected at low multiplicity in the presence or absence of the p38 inhibitor SB203580, the mnk inhibitor CGP57380, or rapamycin. After 5 d, cell-free lysates were prepared by freeze-thawing and titered in Vero cells. (C) NHDF cells growth arrested and treated as in $A$ were either mock infected or infected with wild-type (WT) HSV-1 Patton at the indicated multiplicities. After a 1-h pulse with ${ }^{35} \mathrm{~S}$ amino acids at $14 \mathrm{~h}$ postinfection, cell-free lysates were prepared and either immunoprecipitated with anti-HSV-1 antisera (MOI = 0.01) followed by SDS-PAGE, or directly analyzed by SDS-PAGE (MOI $=1$ and 10$)$.

minished as the dose of input virus increased over a 100fold range. Although the greatest reduction in translation rates was observed at a MOI of 0.01 and some effects of the compounds were discernible at $\mathrm{MOI}=1$, we were unable to detect a reduction in viral translation rates in cells infected at MOI $=10$ despite the fact that SB203580 and CGP57380 were effective at preventing eIF4E phosphorylation and rapamycin abrogated 4E-BP1 phosphorylation (Fig. 8A,C). Thus, eIF4E phosphorylation is required to enhance viral translation rates at low input doses of virus, but this requirement can be effectively bypassed when infections are performed using high input doses of virus. Phenotypes dependent on the multiplicity of infection are common among viruses deficient in a key regulatory protein, like the HSV-1 ICP0 or Adenovirus Ela polypeptides, which are required for replication only at relatively low levels of input viral genomes (Nevins 1981; Stow and Stow 1986; Sacks and Schaffer 1987). Furthermore, the reduction in HSV-1 translation rates observed in quiescent cells infected with low doses of virus and treated with agents that block eIF4E phosphorylation correlates with the observed effects of these same compounds in inhibiting viral replication. Importantly, although the reduction in translation rates is smaller than the corresponding decrease in replication, any relevant comparison must take into account that the replication assay reflects multiple cycles of viral growth, and therefore can compound the effects observed in the course of each growth cycle into very large differences. Rates of translation, on the other hand, were measured during a 1 -h window within a single cycle of growth.

\section{Discussion}

As part of their strategy to commandeer the cellular translational machinery, several viruses effectively hinder host protein synthesis by inhibiting the activity of the translation initiation factor eIF4F (for review, see Schneider and Mohr 2003). Here, we demonstrate that infection with HSV-1 results in the phosphorylation of 
eIF4E, the cap-binding component of eIF4F, and the translational repressor 4E-BP1, enhancing the assembly of eIF4F complexes. In addition to stimulating the eIF4E kinase mnk-1, whose activity is critical for efficient translation of HSV-1 mRNAs and viral replication in quiescent, primary human cells, HSV-1 promotes phosphorylation of the translational repressor 4E-BP1 and its degradation by the cellular proteasome. This is the first demonstration that phosphorylation of eIF4E by the kinase mnk-1 can play a critical role to promote viral replication and establishes that the proteasome can control the steady-state levels of 4E-BP1. The modifications of eIF4E and 4E-BP1 that occur in HSV-1-infected cells require the viral immediate-early ICP0 gene product, a multifunctional regulatory protein that promotes vegetative viral replication and enhances reactivation from latency. This mobilization of the translation machinery may play a critical role in the ability of a latent virus to reenter the vegetative growth cycle and produce viral polypeptides in resting cells such as neurons.

After establishing a latent infection in neurons, HSV-1 periodically replicates productively in neurons and terminally differentiated epithelial cells (for review, see Roizman and Knipe 2001). Our studies suggest that the virus has the ability to mobilize the translational machinery in quiescent cells, ensuring that its mRNAs are translated efficiently. This activity is critical at low input doses of virus, a physiologically relevant condition that occurs when productive replication initiates in a latently infected neuron. Interfering with the eIF4E kinase mnk-1 significantly reduced viral yield and diminished viral translation rates in quiescent, primary human cells infected with low input doses of virus, illustrating the importance of this pathway to productive viral replication. The viral gene(s) responsible for promoting phosphorylation of eIF4E and 4E-BP1 might therefore be critical for pathogenesis. Consistent with this possibility, ICPO mutant viruses are deficient in their ability to reactivate from the latent state (Cai et al. 1993; Halford and Schaffer 2001). In cultured cells, the ICP0 gene product is required for viral replication following low multiplicity infections, but is dispensable for growth following high multiplicity infections (Stow and Stow 1986; Sacks and Schaffer 1987), revealing a striking parallel with the multiplicity-dependent effects displayed by the eIF4E kinase inhibitors. At high MOIs, the larger number of genomes delivered per infected cell bypasses the need for ICP0 function, and viral gene expression proceeds in the absence of the ICP0 protein under these conditions. Likewise, at high MOIs, preventing eIF4E phosphorylation has little effect on translation, possibly reflecting the fact that the ICP0 protein is not required for gene expression under these conditions. Perhaps the amount of viral mRNA produced by a large number of input genomes per cell at high MOIs might be sufficient such that the requirement for eIF4E phosphorylation is now obviated.

The ICPO gene encodes an important viral regulatory protein with multiple activities (for review, see Everett 2000). Whereas the ICP0 gene product is clearly required for eIF4E and 4E-BP1 phosphorylation in HSV-1-infected cells, it might achieve this end by directly triggering the respective cellular signaling pathways involved, or by virtue of its transactivation ability induce the production of other viral gene products prior to the late stage of the growth cycle that subsequently engage p38 and mTOR. Thus, although intensive investigation is required to distinguish between these possibilities and determine which of the $\sim 80$ known HSV-1-encoded genes, either alone or in combination, participate in this process, this study definitively establishes that the stimulation of eIF4E phosphorylation observed in HSV-1-infected cells requires the ICPO gene product, enhancing viral translation and replication in quiescent cells.

The targeted degradation of 4E-BP1 we observe raises important questions regarding the mechanism through which this is achieved. Rapamycin inhibits the mTOR kinase, preventing 4E-BP1 phosphorylation and the release of bound eIF4E (for review, see Gingras et al. 2001). Moreover, we now demonstrate that rapamycin also prevents 4E-BP1 degradation in HSV-1-infected cells. As 4E$\mathrm{BP} 1$ remains associated with eIF4E in infected cells treated with rapamycin, it is conceivable that free 4EBP1 is somehow earmarked for degradation in HSV-1infected cells. Thus, binding to eIF4E might not only serve to prevent eIF4E from associating with eIF4G to form a functional eIF4F complex, but also may stabilize the 4E-BP1 translational repressor. Once phosphorylated, rapid degradation would ensure that cellular phosphatases are unable to dephosphorylate 4E-BP1, restoring its ability to bind eIF4E. Finally, the impairment of host protein synthesis in HSV-1-infected cells prevents the cell from reestablishing translational repression by inhibiting synthesis of new 4E-BP1 molecules. A related situation was recently described following fertilization in sea urchins, where an increase in translation correlates with 4E-BP1 phosphorylation and its subsequent degradation. However, the proteolytic pathway responsible for 4E-BP1 degradation was not identified in this study (Salaun et al. 2003). Our work establishes that upon phosphorylation, 4E-BP1 can be degraded by the proteasome, and that 4E-BP1 phosphorylation correlates with its stability in human cells. Thus, phosphorylation, and possibly the stability of 4E-BP1, may potentially impinge on a variety of cellular processes ranging from translational control, regulation of cell growth, and transformation by retroviral oncogenes (Sonenberg and Gingras 1998; Fingar et al. 2002, 2004; Akoi and Vogt 2004). Although the contribution of 4E-BP1 phosphorylation and degradation to HSV-1 replication was minimal because of the low abundance of 4E-BP1 relative to eIF4E in quiescent human fibroblasts, the ability of HSV-1 to relieve translational repression established by 4E-BP1 might prove to be vital for its replication in other cell types where 4E-BP1 levels exceed the amount of eIF4E.

Despite the fact that HSV-1 stimulates eIF4E phosphorylation and promotes the assembly of eIF4F complexes to enhance the synthesis of viral proteins, other factors are likely to play a role in the selective transla- 
tion of viral mRNAs and the impairment of host polypeptide synthesis. These include, but may not be limited to, viral functions that reduce the transcription of host genes (for review, see Roizman and Knipe 2001), inhibit mRNA splicing (Sciabica et al. 2003), and enhance the global turnover of both viral and cellular mRNA within the cell (Elgadi et al. 1999; Everly et al. 2002). To date, no common cis-acting elements have been identified in HSV-1 mRNAs that are capable of fostering their preferential translation in infected cells. Although cellular mRNA pools are depleted, selective translation of viral mRNAs might simply be achieved through the sheer abundance of functional viral mRNAs, compared with cellular mRNA, continually produced in infected cells. The requirement for eIF4E phosphorylation in quiescent cells might have little to do with the impairment of host protein synthesis and everything to do with activating the translational machinery in a resting cell to maximize the translation of viral gene products.

Although it is accepted that dephosphorylation of eIF4E contributes to the inhibition of host translation observed in cells infected with Adenovirus or VSV (Cuesta et al. 2000b; Connor and Lyles 2002), the role of eIF4E phosphorylation in general translational control remains controversial. Whereas some reports correlate eIF4E phosphorylation with rates of protein synthesis (Bonneau and Sonenberg 1987; Huang and Schneider 1991; Boal et al. 1993; Morley et al. 1993; Beretta et al. 1998; Pyronnet et al. 2001; Takei et al. 2001; Dyer et al. 2003), other studies have questioned whether eIF4E phosphorylation is truly required for translation (McKendrick et al. 2001; Morley and Naegale 2002; Knauf et al. 2001; reviewed in Scheper and Proud 2002). Instead, several models have been proposed suggesting that eIF4E phosphorylation, although not absolutely required for translation initiation, somehow enhances the rate with which eIF4F complexes initiate protein synthesis (Morley and Naegele 2002; Scheper et al. 2002). Indeed, flies containing an eIF4E allele encoding a polypeptide that cannot be phosphorylated are viable, albeit smaller than their wild-type counterparts (Lachance et al. 2002). This latter finding clearly demonstrates that eIF4E phosphorylation is not essential for translation, but the reduced size phenotype is consistent with its playing an important biological role. Our data demonstrating that mnk-1 activity is required to enhance HSV-1 mRNA translation and viral replication in quiescent cells infected with low input doses of virus defines a situation in which eIF4E phosphorylation, while not absolutely required for translation, is critical to enhance viral translation rates and promote viral growth.

\section{Materials and methods}

\section{Cells and viruses}

293, Vero, and U373 cells were obtained from ATCC and cultured as described (Mulvey et al. 2003). Primary human foreskin fibroblasts, FS4 (Jan Vilcek, New York University School of
Medicine, New York, NY) and NHDF (Clonetics), were cultured in DMEM containing $5 \%$ (FS4) or $10 \%$ (NHDF) fetal bovine serum.

HSV-1 (wild-type strains Patton and KOS) was prepared in Vero cells. tsB7(B) (Batterson et al. 1983) was obtained from Bernard Roizman (University of Chicago, Chicago, IL). The ICPO null mutant 7134 (Cai and Schaffer 1989) and the repaired 7134R virus were obtained from P. Schaffer (Harvard Medical School, Boston, MA). UV-inactivated virus was prepared by exposing 1-mL layers of virus stock in a six-well dish to six pulses of $0.12 \mathrm{~J} / \mathrm{cm}^{2}$ of UV light in a Stratalinker (Stratagene). One day prior to infection, cells were seeded in a six-well dish at the following densities: U373 or Vero cells $\left(5 \times 10^{5}\right.$ cells per well); 293 cells $\left(1 \times 10^{6}\right.$ cells per well); FS4 or NHDF cells $\left(3 \times 10^{5}\right.$ cells per well). Cells were infected the following day at an MOI of 10, unless otherwise indicated. Mock infections were performed with a cell-free lysate prepared from uninfected Vero cells. The levels of p38 activation, phosphorylated eIF4E, and phosphorylated 4E-BP1 present in cells treated with Vero cell lysates were indistinguishable from those observed in cells mock-infected with DMEM $+1 \%$ CS. Cells to be infected with the temperature-sensitive mutant tsB7(B) were seeded at half the cell densities described above $2 \mathrm{~d}$ prior to infection. The day before infection, cells were placed in DMEM $+2 \%$ FBS and incubated at either $33.5^{\circ} \mathrm{C}$ or $39.5^{\circ} \mathrm{C}$ and allowed to equilibrate overnight before being infected with tsB7(B) at an MOI of 3 .

\section{Antibodies and chemicals}

eIF4E (catalog \#E27620) and eIF4G (catalog \#E46520) antibodies were obtained from BD Transduction Laboratories. Mouse monoclonal anti-eIF4A antibody was a kind gift of R. Schneider (New York University School of Medicine, New York, NY), and the anti - Us11 monoclonal antibody was generously supplied by R. Roller (University of Iowa, Iowa City, IA). 4EBP1 antibody (catalog \#9452) and phospho-specific antibodies against p38 MAPK (catalog \#9216) and ERK (catalog \#9101) were obtained from Cell Signaling Technologies. The 4E-BP1 antibody A300501A was from Bethyl Laboratories. Chemical inhibitors were dissolved as $1000 \times$ stocks in DMSO and used at the concentrations indicated. PD98059 $(50 \mu \mathrm{M})$, SB203580 $(10 \mu \mathrm{M})$, and rapamycin $(100 \mathrm{nM})$ were obtained from Calbiochem; phosphonoacetic acid $(300 \mu \mathrm{g} / \mathrm{mL})$ was obtained from Sigma; and CGP57380 $(20 \mu \mathrm{M})$ was a generous gift of $\mathrm{H}$. Gram (Novartis Pharma, Basel, Switzerland). Cells were pretreated with inhibitors for $1 \mathrm{~h}$ prior to infection and then infected in the continuous presence of inhibitor.

\section{Western blotting and isoelectric focusing}

Total cellular protein was solubilized in $250 \mu \mathrm{L}$ of sample buffer (62.5 mM Tris- $\mathrm{HCl}$ at $\mathrm{pH} 6.8,2 \%$ SDS, 10\% glycerol, $0.7 \mathrm{M}$ $\beta$-mercaptoethanol), boiled for $3 \mathrm{~min}$, fractionated by SDSPAGE, and transferred to nitrocellulose. Immunoblots were processed and developed using the ECL reagent according to the manufacturer's instructions (Amersham). Vertical Slab Isoelectric Focusing (IEF) was performed as described (Morley and Pain 1995; Walsh et al. 2003).

\section{Analysis of eIF4E-binding proteins}

Sepharose 4B and 7-Methyl GTP-Sepharose 4B (Cat \# 27-502501) was obtained from Amersham Pharmacia Biotech. After washing with PBS, $1.5 \times 10^{6}$ cells were lysed in $1 \mathrm{~mL}$ of NLB (50 $\mathrm{mM}$ HEPES at $\mathrm{pH} 7.4,150 \mathrm{mM} \mathrm{NaCl}, 2 \mathrm{mM}$ EDTA, $2 \mathrm{mM}$ 
$\mathrm{Na}_{3} \mathrm{VO}_{4}, 25 \mathrm{mM}$ glycerophosphate, Complete Mini protease inhibitor cocktail [Roche], and 0.5\% NP-40) and extracts clarified by centrifugation at $10,000 \times \mathrm{g}\left(10 \mathrm{~min}, 4^{\circ} \mathrm{C}\right)$. Supernatants precleared with Sepharose 4B $(30 \mu \mathrm{L}$ of settled bed volume for 20 min) were next incubated with 7-Methyl GTP-Sepharose 4B (50 $\mu \mathrm{L}$ of settled bed volume) for $1 \mathrm{~h}$ at $4^{\circ} \mathrm{C}$. Pelleted beads were washed four times with $0.5 \mathrm{~mL}$ of NLB, and resuspended in 0.6 $\mathrm{mL}$ of NLB $+1 \mathrm{mM}$ GTP for $1 \mathrm{~h}$ at $4^{\circ} \mathrm{C}$. Following a final four washes with $0.5 \mathrm{~mL}$ of $\mathrm{NLB}$, the beads were suspended in sample buffer and boiled, and the bound proteins were analyzed by SDS-PAGE and immunoblotting.

\section{Multicycle growth experiments}

NHDF cells $\left(8 \times 10^{5}\right.$ cells/dish) were seeded in $60-\mathrm{mm}$ dishes and allowed to attach overnight. The next day, cells were washed three times in PBS and refed with DMEM + 0.2\% FBS. Propidium iodide staining of cultures after 24, 48, 72, and $96 \mathrm{~h}$, followed by flow cytometry, revealed that maximal growth arrest $(98 \%$ of cells) was achieved after $72 \mathrm{~h}$ of serum starvation. Growth-arrested cells were pretreated for $1 \mathrm{~h}$ with SB203580, CGP57380, rapamycin, or an equal volume of DMSO and subsequently infected (MOI $=10^{-4}$ ) with wild-type HSV-1 (Patton). After $5 \mathrm{~d}$, cultures were lysed by freeze-thawing and the virus produced was quantified by plaque assay in Vero cells.

\section{Immunoprecipitation of HSV-1 proteins}

Infected cultures $\left(1.5 \times 10^{6}\right.$ cells $)$ were lysed in NLB and clarified as described above. To each supernatant, precleared with normal rabbit serum and Protein A Sepharose (PAS), $10 \mu \mathrm{L}$ (40 $\mu \mathrm{g}$ ) of anti-HSV-1 antibody (Maine Biotechnology, USA; catalog no. PAB7119P) was added and the samples were incubated for 2 $\mathrm{h}$ at $4^{\circ} \mathrm{C}$. PAS ( $30 \mu \mathrm{L}$ of settled bed volume) was subsequently added, and the incubation was continued for $1 \mathrm{~h}$. The beads were collected by brief centrifugation and washed three times in $0.5 \mathrm{~mL}$ of NLB. Immune complexes were fractionated by SDSPAGE.

\section{Acknowledgments}

We thank Priscilla Schaffer, Richard Roller, Bernard Roizman, Bob Schneider, Jan Vilcek, John Blaho, and Hermann Gram for generously providing reagents; members of the Mohr lab for helpful discussions; and Michael Garabedian, Angus Wilson, Matt Mulvey, and Irma Sanchez for their helpful, critical comments on the manuscript. This work was supported by a grant from the National Institutes of Health to I.M.

The publication costs of this article were defrayed in part by payment of page charges. This article must therefore be hereby marked "advertisement" in accordance with 18 USC section 1734 solely to indicate this fact.

\section{References}

Akoi, M. and Vogt, P. 2004. Retroviral oncogenes and TOR. Curr. Top. Microbiol. Immunol. 279: 321-338.

Batterson, W., Furlong, D., and Roizman, B. 1983. Molecular genetics of herpes simplex virus. VIII. Further characterization of a temperature-sensitive mutant defective in release of viral DNA and in other stages of the viral reproductive cycle. J. Virol. 45: 397-407.

Beretta, L., Singer, N.G., Hinderer, R., Gingras, A.-C., Richardson, B., Hanash, S.M., and Sonenberg, N. 1998. Differential regulation of translation and eIF4E phosphorylation during human thymocyte maturation. J. Immunol. 160: 3269-3273.
Boal, T.R., Chiorini, J.A., Cohen, R.B., Miyamoto, S., Frederickson, R.M., Sonenberg, N., and Safer, B. 1993. Regulation of eukaryotic translation initiation factor expression during T-cell activation. Biochim. Biophys. Acta 1176: 257-264.

Bonneau, A.M. and Sonenberg, N. 1987. Involvement of the $24-\mathrm{kDa}$ cap-binding protein in the regulation of protein synthesis in mitosis. J. Biol. Chem. 262: 11134-11139.

Boutell, C., Sadis, S., and Everett, R.D. 2002. Herpes simplex virus type 1 immediate-early protein ICPO and is isolated RING finger domain act as ubiquitin E3 ligases in vitro. J. Virol. 76: 841-850.

Cai, W.Z. and Schaffer, P.A. 1989. Herpes simplex virus type 1 ICP0 plays a critical role in the de novo synthesis of infectious virus following transfection of viral DNA. I. Virol. 63: 4579-4589.

Cai, W., Astor, T.L., Liptak, L.M., Cho, C., Coen, D.M., and Schaffer, P.A. 1993. The herpes simplex virus type 1 regulatory protein ICPO enhances virus replication during acute infection and reactivation from latency. J. Virol. 67: 75017512 .

Connor, J.H. and Lyles, D.S. 2002. Vesicular stomatitis virus infection alters the eIF4F translation initiation complex and causes dephosphorylation of the eIF4E binding protein 4EBP1. J. Virol. 76: 10177-10187.

Cuesta, R., Laroia, G., and Schneider, R.J. 2000a. Chaperone hsp27 inhibits translation during heat shock by binding eIF4G and facilitating dissociation of cap-initiation complexes. Genes \& Dev. 14: 1460-1470.

Cuesta, R., Xi, Q., and Schneider, R.J. 2000b. Adenovirus-specific translation by displacement of kinase Mnk1 from capinitiation complex eIF4F. EMBO J. 19: 3465-3474.

Dyer, J.R., Michel, S., Lee, W., Castellucci, V.F., Wayne, N.L., and Sossin, W.S. 2003. An activity-dependent switch to capindependent translation triggered by eIF4E dephosphorylation. Nat. Neurosci. 6: 219-220.

Elgadi, M.M., Hayes, C.E., and Smiley, J.R. 1999. The herpes simplex virus vhs protein induces endoribonucleolytic cleavage of target RNAs in cell extracts. J. Virol. 73: 71537164.

Everett, R.D. 2000. ICP0, a regulator of herpes simplex virus during lytic and latent infection. Bioessays 22: 761-770.

Everly Jr., D.N., Feng, P., Mian, I.S., and Read, G.S. 2002. mRNA degradation by the virion host shutoff (Vhs) protein of herpes simplex virus: Genetic and biochemical evidence that Vhs is a nuclease. J. Virol. 76: 8560-8571.

Feigenblum, D. and Schneider, R.J. 1996. Cap-binding protein (eukaryotic initiation factor $4 \mathrm{E}$ ) and $4 \mathrm{E}$-inactivating protein BP-1 independently regulate cap-dependent translation. Mol. Cell. Biol. 16: 5450-5457.

Feng, P., Everly Jr., D.N., and Read, G.S. 2001. mRNA decay during herpesvirus infections: Interaction between a putative viral nuclease and a cellular translation factor. J. Virol. 75: 10272-10280.

Fingar, D.C., Salama, S., Tsou, C., Harlow, E., and Blenis, J. 2002. Mammalian cell size is controlled by $\mathrm{mTOR}$ and its downstream targets, S6K1 and 4E-BP1/eIF4E. Genes \& Dev. 16: $1472-1487$.

Fingar, D.C., Richardson, C.J., Tee, A.R., Cheatham, L., Tsou, C., and Blenis, J. 2004. mTOR controls cell cycle progression through its cell growth effectors S6K and 4E-BP1/eukaryotic translation initiation factor 4E. Mol. Cell. Biol. 24: 200216.

Fukunaga, R. and Hunter, T. 1997. MNK1, a new MAP kinaseactivated protein kinase, isolated by a novel expression screening method for identifying protein kinase substrates. EMBO I. 16: 1921-1933. 
Gingras, A.-C., Raught, B., and Sonenberg, N. 1999. eIF4 initiation factors: Effectors of mRNA recruitment to ribosomes and regulators of translation. Annu. Rev. Biochem. 68: 913-963.

- 2001. Regulation of translation initiation by FRAP/ mTOR. Genes \& Dev. 15: 807-826.

Haghighat, A., Mader, S., Pause, A., and Sonenberg, N. 1995. Repression of cap-dependent translation by 4E-binding protein 1: Competition with p220 for binding to eukaryotic initiation factor-4E. EMBO I. 14: 5701-5709.

Halford, W.P. and Schaffer, P.A. 2001. ICP0 is required for efficient reactivation of herpes simplex virus type 1 from neuronal latency. J. Virol. 75: 3240-3249.

Huang, J.T. and Schneider, R.J. 1991. Adenovirus inhibition of cellular protein synthesis involves inactivation of cap-binding protein. Cell 65: 271-280.

Knauf, U., Tschopp, C., and Gram, H. 2001. Negative regulation of protein translation by mitogen-activated protein kinaseinteracting kinases 1 and 2. Mol. Cell. Biol. 21:55005511.

Lachance, P.E., Miron, M., Raught, B., Sonenberg, N., and Lasko, P. 2002. Phosphorylation of eukaryotic translation initiation factor 4E is critical for growth. Mol. Cell. Biol. 22: $1656-1663$.

Mader, S., Lee, H., Pause, A., and Sonenberg, N. 1995. The translation initiation factor eIF-4E binds to a common motif shared by the translation factor eIF-4G and the translational repressors 4E-binding proteins. Mol. Cell. Biol. 15: 49904997.

Marcotrigiano, J., Gingras, A.C., Sonenberg, N., and Burley, S.K. 1999. Cap-dependent translation initiation in eukaryotes is regulated by a molecular mimic of eIF4G. Mol. Cell 3: 707716.

McKendrick, L., Morley, S.J., Pain, V.M., Jagus, R., and Joshi, B. 2001. Phosphorylation of eukaryotic initiation factor $4 \mathrm{E}$ (eIF4E) at Ser209 is not required for protein synthesis in vitro and in vivo. Eur. J. Biochem. 268: 5375-5385.

McLean, T.I. and Bachenheimer, S.L. 1999. Activation of cJun $\mathrm{N}$-terminal kinase by herpes simplex virus type 1 enhances viral replication. J. Virol. 73: 8415-8426.

Morley, S.J. and McKendrick, L. 1997. Involvement of stressactivated protein kinase and p38/RK mitogen activated protein kinase signaling pathways in the enhanced phosphorylation of initiation factor 4E in NIH 3T3 cells. J. Biol. Chem. 272: $17887-17893$.

Morley, S.J. and Naegele, S. 2002. Phosphorylation of eukaryotic initiation factor (eIF) 4E is not required for de novo protein synthesis following recovery from hypertonic stress in human kidney cells. J. Biol. Chem. 277: 32855-32859.

Morley, S.J. and Pain, V.M. 1995. Translational regulation during activation of porcine peripheral blood lymphocytes: Association and phosphorylation of the $\alpha$ and $\gamma$ subunits of the initiation factor complex eIF-4F. Biochem. I. 312: 627635.

Morley, S.J., Rau, M., Kay, J.E., and Pain, V.M. 1993. Increased phosphorylation of eukaryotic initiation factor $4 \alpha$ during activation of $\mathrm{T}$ lymphocytes correlates with increased eIF-4F complex formation. Eur. J. Biochem. 218: 39-48.

Mulvey, M., Poppers, J., Sternberg, D., and Mohr, I. 2003. Regulation of eIF $2 \alpha$ phosphorylation by different functions that act during discrete phases in the herpes simplex virus type 1 life cycle. J. Virol. 77: 10917-10928.

Nevins, J.R. 1981. Mechanism of activation of early viral transcription by the adenovirus E1a gene product. Cell 26: $213-$ 220.

Pyronnet, S., Imataka, H., Gingras, A.-C., Fukunaga, R., Hunter, T., and Sonenberg, N. 1999. Human eukaryotic translation initiation factor $4 \mathrm{G}$ (eIF4G) recruits mnk1 to phosphorylate eIF4E. EMBO J. 18: 270-279.

Pyronnet, S., Dostie, J., and Sonenberg, N. 2001. Suppression of cap-dependent translation in mitosis. Genes \& Dev. 15: 2083-2093.

Rogers Jr., G.W., Komar, A.A., and Merrick, W.C. 2002. eIF4A: The godfather of the DEAD box helicases. Prog. Nucleic Acid Res. Mol. Biol. 72: 307-331.

Roizman, B. and Knipe, D. 2001. Herpes simplex viruses and their replication. In Field's virology, 4th ed. (eds. D.M. Knipe and P.M. Howley), Vol. 2, pp. 2399-2459. Lippincott, Williams and Wilkins, Philadelphia, PA.

Sacks, W.R. and Schaffer, P.A. 1987. Deletion mutants in the gene encoding the herpes simplex virus type 1 immediateearly protein ICPO exhibit impaired growth in cell culture. J. Virol. 61: 829-839.

Salaun, P., Pyronnet, S., Morales, J., Mulner-Lorillon, O., Belle, R., Sonenberg, N., and Cormier, P. 2003. eIF4E/4E-BP dissociation and 4E-BP degradation in the first mitotic division of the sea urchin embryo. Dev. Biol. 255: 428439.

Scheper, G.C. and Proud, C.G. 2002. Does phosphorylation of the cap-binding protein eIF4E play a role in translation initiation? Eur. J. Biochem. 269: 5350-5359.

Scheper, G.C., Morrice, N.A., Kleijn, M., and Proud, C.G. 2001. The mitogen-activated protein kinase signal-integrating kinase Mnk2 is a eukaryotic initiation factor $4 \mathrm{E}$ kinase with high levels of basal activity in mammalian cells. Mol. Cell. Biol. 21: 743-754.

Scheper, G.C., van Kollenburg, B., Hu, J., Luo, Y., Goss, D.J., and Proud, C.G. 2002. Phosphorylation of eukaryotic initiation factor 4E markedly reduces its affinity for capped mRNA. J. Biol. Chem. 277: 3303-3309.

Schneider, R.J. and Mohr, I. 2003. Translation initiation and viral tricks. Trends Biochem. Sci. 28: 130-136.

Sciabica, K.S., Dai, Q.J., and Sandri-Goldin, R.M. 2003. ICP27 interacts with SRPK1 to mediate HSV splicing inhibition by altering SR protein phosphorylation. EMBO J. 22: 1608 1619.

Sonenberg, N. and Gingras, A.C. 1998. The mRNA 5' cap binding protein eIF4E and control of cell growth. Curr. Opin. Cell. Biol. 10: 268-275.

Stanners, C.P. and Becker, H. 1971. Control of macromolecular synthesis in proliferating and resting Syrian hamster cells in monolayer culture. I. Ribosome function. I. Cell. Physiol. 77: 31-42.

Stow, N.D. and Stow, E.C. 1986. Isolation and characterization of a herpes simplex virus type 1 mutant containing a deletion within the gene encoding the immediate early polypeptide Vmw110. J. Gen. Virol. 67: 2571-2585.

Takei, N., Kawamura, M., Hara, K., Yonezawa, K., and Nawa, H. 2001. Brain-derived neurotrophic factor enhances neuronal translation by activating multiple initiation processes: Comparison with the effects of insulin. J. Biol. Chem. 276: 42818-42825.

Thomas, G. and Gordon, J. 1979. Regulation of protein synthesis during the shift of quiescent animal cells into the proliferative state. Cell Biol. Int. Rep. 3: 307-320.

Thomas, G. and Thomas, G. 1986. Translational control of mRNA expression during the early mitogenic response in Swiss mouse 3T3 cells: Identification of specific proteins. J. Cell. Biol. 103: 2137-2144.

Thomas, G., Thomas, G., and Luther, H. 1981. Transcriptional and translational control of cytoplasmic proteins after serum stimulation of quiescent Swiss 3T3 cells. Proc. Nat1. Acad Sci. 78: 5712-5716. 
Tuazon, P.T., Morley, S.J., Dever, T.E., Merrick, W.C., Rhoads, R.E., and Traugh, J.A. 1990. Association of initiation factor eIF-4E in a cap binding protein complex (eIF-4F) is critical for and enhances phosphorylation by protein kinase C. J. Biol. Chem. 265: 10617-10621.

Van Sant, C., Hagglund, R., Lopez, P., and Roizman, B. 2001. The infected cell protein 0 of herpes simplex virus 1 dynamically interacts with proteasomes, binds and activates the cdc34 E2 ubiquitin-conjugating enzyme, and possesses in vitro E3 ubiquitin ligase activity. Proc. Nat1. Acad. Sci. 98: 8815-8820.

Walsh, D., Meleady, P., Power, B., Morley, S.J., and Clynes, M. 2003. Increased levels of the translation initiation factor eIF4E in differentiating epithelial lung tumor cell lines. Differentiation 71: 126-134.

Wang, X., Flynn, A., Waskiewicz, A.J., Webb, B.L.J., Vries, R.G., Baines, I.A., Cooper, J., and Proud, C.G. 1998. The phosphorylation of eukaryotic initiation factor eIF4E in response to phorbol esters, cell stresses and cytokines is mediated by distinct MAP kinase pathways. J. Biol. Chem. 273: 93739377.

Waskiewicz, A.J., Flynn, A., Proud, C.G., and Cooper, J.A. 1997. Mitogen-activated protein kinases activate the serine/threonine kinases mnk1 and mnk2. EMBO J. 16: 1909-1920.

Waskiewicz, A.J., Johnson, J.C., Penn, B., Mahalingam, M., Kimball, S.R., and Cooper, J.A. 1999. Phosphorylation of the capbinding protein eukaryotic translation factor $4 \mathrm{E}$ by protein kinase mnk1 in vivo. Mol. Cell. Biol. 19: 1871-1880.

Zachos, G., Clements, B., and Conner, J. 1999. Herpes simplex virus type 1 infection stimulates p38/c-Jun N-terminal mitogen-activated protein kinase pathways and activates transcription factor AP-1. J. Virol. 274: 5097-5103. 


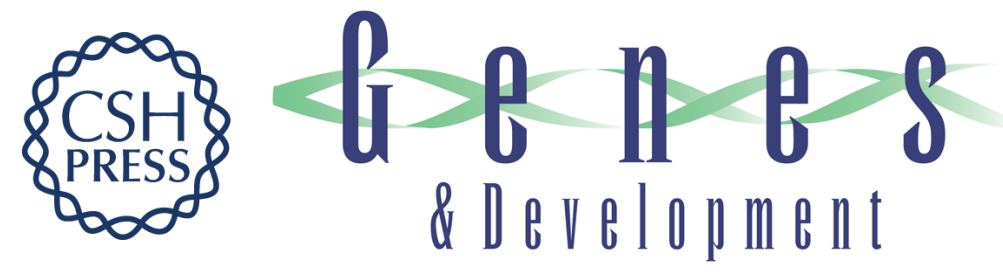

\section{Phosphorylation of elF4E by Mnk-1 enhances HSV-1 translation and replication in quiescent cells}

Derek Walsh and lan Mohr

Genes Dev. 2004, 18:

Access the most recent version at doi:10.1101/gad.1185304

References This article cites 61 articles, 39 of which can be accessed free at: http://genesdev.cshlp.org/content/18/6/660.full.htmI\#ref-list-1

License

Email Alerting

Receive free email alerts when new articles cite this article - sign up in the box at the top Service right corner of the article or click here.

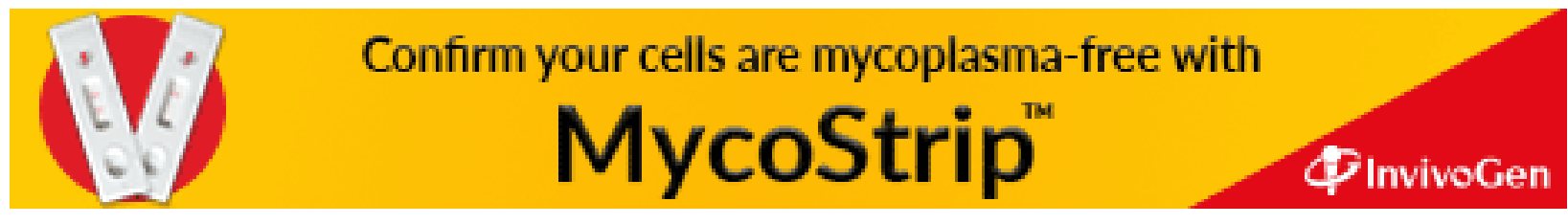

